Therapeutics

\section{Comparative effectiveness of combination treatment for hypertension in black Africans}

10.1136/bmjebm-2019-111251

Check for updates

Igho Onakpoya

Nuffield Department of Primary Care Health Sciences, University of Oxford, Oxford, UK

Correspondence to: Dr Igho Onakpoya, Nuffield Department of Primary Care Health Sciences, University of Oxford, OX2 6GG, UK; igho.onakpoya@phc.ox.ac.uk

Although different combination therapies are currently used for treating hypertension among blacks, the authors of a recently published trial suggest amlodipine plus either hydrochlorothiazide or perindopril is a more effective combination.

Calcium channel blockers are usually recommended as firstline treatment for control of hypertension. ${ }^{1}$ Among blacks, one or more antihypertensive medications are added to calcium channel blockers when sole treatment is inadequate for blood pressure control. However, there is uncertainty about which drug combination is more effective for use as combination therapy. In the UK for instance, the National Institute for Health and Care Excellence recommends use of either an ACE inhibitor, an angiotensin receptor blocker (ARB), or a thiazide-like diuretic as second-line. ${ }^{2}$

In a recently published single-blinded, three-arm, multicountry study $(n=728),{ }^{3}$ the authors compared the effectiveness of $5 \mathrm{mg}$ of amlodipine (a calcium channel blocker) plus $12.5 \mathrm{mg}$ of hydrochlorothiazide (a thiazide), $5 \mathrm{mg}$ of amlodipine plus $4 \mathrm{mg}$ of perindopril (an ACE inhibitor) or $4 \mathrm{mg}$ of perindopril plus $12.5 \mathrm{mg}$ of hydrochlorothiazide in the management of uncontrolled hypertension among blacks living in the sub-Saharan Africa. Their primary outcome was the mean change in 24-hour ambulatory systolic blood pressure between baseline and at 6 months. Secondary outcomes included mean change in 24-hour ambulatory diastolic blood pressure between baseline and at 6 months, change in mean daytime and mean night time ambulatory blood pressures.

At 6 months, and after adjusting for baseline ambulatory systolic blood pressure, participants who received either of the two amlodipine combinations had significantly larger reductions in mean ambulatory systolic blood pressure than those who received perindopril plus hydrochlorothiazide: $-3.14 \mathrm{~mm} \mathrm{Hg}(\mathrm{p}=0.03)$; and mean difference (MD) $-3.00 \mathrm{~mm} \mathrm{Hg}(\mathrm{p}=0.04)$, respectively. Similar results were observed for mean daytime and night time ambulatory blood pressures. There was no significant difference between the group receiving amlodipine plus hydrochlorothiazide and the group receiving amlodipine plus perindopril: $\mathrm{MD}-0.14 \mathrm{~mm} \mathrm{Hg}$ $(p=0.92)$. There were no significant differences in ambulatory diastolic blood pressures between groups.

The investigators used electronic methods to ensure adequate randomisation, there was a high completer rate (95.9\%), and

\section{EBM verdict}

EBM Verdict on: Comparison of dual therapies for lowering blood pressure in black africans. $N$ Engl J Med 2019;380:2429-39. doi: 10.1056/NEJMc1909844.

- Among blacks with hypertension, amlodipine plus either hydrochlorothiazide or perindopril could be a more effective combination for second-line treatment.

appropriate statistical tests were performed. The investigators also included an independent statistician to analyse the trial results.

However, there were limitations. Although the trial was reported as single-blind (investigators), the participants may not have been totally blinded because the interventions were only repackaged-their appearances, shape and taste essentially remained the same. The study did not include participants with comorbidities.

Results of a large observational study have shown that ACE inhibitors may not be effective for treatment of hypertension in blacks. ${ }^{4}$ Indeed in the UK, ARBs are preferred to ACE inhibitors as second-line. ${ }^{5}$ Therefore, it seems unlikely the results of this study will change current clinical practice guidelines on blood pressure management in black populations. Future studies in this area should include an ARB arm (and/or other antihypertensives with different mechanisms of action) to assess the comparative effectiveness of drug combination therapies.

Twitter Igho Onakpoya @IOnakpoya

Contributors I am the sole author of this paper.

Competing interests None declared.

Patient consent for publication Not required.

Provenance and peer review Not commissioned; externally peer reviewed.

( $)$ Author(s) (or their employer(s)) 2020. No commercial re-use. See rights and permissions. Published by BMJ.

To cite: Onakpoya I. BMJ Evidence-Based Medicine 2020;25:112.

ORCID iD

Igho Onakpoya http://orcid.org/0000-0002-2420-0811

\section{References}

1 Burnier M, Pruijm M, Wuerzner G. Treatment of essential hypertension with calcium channel blockers: what is the place of lercanidipine? Expert Opin Drug Metab Toxicol 2009;5:981-7.

2 UK National Institute for Health and Care Excellence. Hypertension in adults: diagnosis and management. Available: https://www.nice.org.uk/ guidance/ng 136/chapter/Recommendations\#ftn.footnote_3 [Accessed 31 Aug 2019].

3 Ojji DB, Mayosi B, Francis V, et al. Comparison of dual therapies for lowering blood pressure in black Africans. $N$ Engl J Med 2019;380:2429-39.

4 Ogedegbe G, Shah NR, Phillips C, et al. Comparative effectiveness of angiotensin-converting enzyme inhibitor-based treatment on cardiovascular outcomes in hypertensive blacks versus whites. J Am Coll Cardiol 2015;66:1224-33.

5 UK National Institute for Health and Care Excellence. Hypertension in adults: diagnosis and management. Clinical guideline [CG127]. Available: https://www.nice.org.uk/guidance/cg127/chapter/1-Guidance\#choosingantihypertensive-drug-treatment-2 [Accessed 18 Aug, 2019]. 